\title{
'Every human being is an artist': From social representation to creative experiences of Self
}

\author{
Julian Manley
}

\section{Introduction}

In a chapter I wrote for the first Researching Beneath the Surface book (Clarke and Hoggett, 2009), I suggested that there was room within the panoply of psycho-social methods for a method focussed on visual imagery and affect rather than words (Manley 2009). In this chapter called 'Words are not enough', I concluded that psycho-social studies should work towards an understanding of how unconscious images are intimately linked to affect; an inclusion of this understanding in our research; and the creation of new methodologies that allow for the assessment and evaluation of affect in psycho-social research (p. 96). The reason for needing to do this was, I suggested, to reach the 'beneath the surface' understandings of complex situations that defied discursive explanations. At the time of writing, 2009, it was only social dreaming (Lawrence 2005; Manley 2014) - with its emphasis on dream images and free association - that went some way towards satisfying these demands. However, at the time, social dreaming was largely practice-based rather than research-orientated. Work using social dreaming in research is now underway (Manley and Trustram 2016; Karolia and Manley 2017; Berman and Manley 2017), however, until recently the practice-based orientation of social dreaming had stymied its development as a psycho-social research method (Manley 2009). Furthermore, the use of dreams is itself problematical, since they are perhaps our most abstract and incomprehensible expressions of thought, undoubtedly emerging from our unconscious and difficult to interpret with any degree of certainty. This is partly a philosophical and epistemological question. In other words, it depends on your point of view. In 2009 , I went on to say that it would be easier to accept the use of social dreaming and related methods in research by approaching them from a Deleuzian lens. It was through Deleuzian ideas of 'affect, 'difference' and 'becoming', that I tried to make sense of aspects of working with the visual imagination (Manley 2009).

The method discussed in the present chapter - the visual matrix - is the result of the development of these thoughts. In the visual matrix we do away with social dreaming's emphasis on dreams but continue with the use of imagery in the mind and free association. As in social dreaming, we are primarily concerned with how the expression of affect through shared unconscious images and visualisations can help us to discover and understand complexities that would otherwise remain hidden and unexpressed. In developing the visual matrix with colleagues at the Psychosocial Research Unit at the University of Central Lancashire, the focus has been on developing it as a method for research by locating the visual matrix within the framework of a research topic or question and developing a rigorous analytical method for the interpretation of data (Froggett et al 2015; Manley et al 2016; Manley and Roy 2017). 
In the present chapter, I aim to further explore the usefulness of taking on a Deleuzian approach to the visual matrix. Previous work on the visual matrix has combined various approaches to understanding the method: via Deleuzian concepts of affect and a rhizomatic understanding of how the images make meaning through being inter-linked in web-like patterns, instead of sequences of words in sentences; through Alfred Lorenzer's concept of 'scenic understanding', which suggests that a 'scene' such as that created in the associated images of the visual matrix can be used to describe the moment when the individual in the visual matrix shares with others a symbolic world in images or words; and by references to the world of object relations and psychoanalytically informed thinking, which is more familiar to psychosocial studies, such as Bion's theory of thinking, containment and reverie, and Winnicott's potential space, (Froggett et al 2015, p. 5). The present chapter will try to see how far the visual matrix can be perceived as a truly Deleuzian method, by bringing in further Deleuzian ideas and theories and testing them against a case study that used the visual matrix as the primary research method. In doing so, I will also attempt to situate Deleuze within the possibilities of psycho-social research methods.

\section{The case study: An artwork in the Archive}

The context of the research is an artwork and exhibition called Demolition Street which ran from $5^{\text {th }}$ May- $5^{\text {th }}$ June 2015 at the Lancashire County Archive. Demolition Street is at once a record and an aesthetic expression of the artist William Titley's engagement with the enforced eviction of a community from their homes in Bright Street in a small town in the north west of England.

The artwork, consisted of photography, found objects and videos of the remaining residents talking about their immanent eviction. The videos were located inside and outside a wooden triangular structure. Inside this structure, the videos depicted the pictures of the interviewees but the audio consisted of only the breaths and gaps in between the spoken words. The videos on the outside showed the opposite, the spoken words with the pauses, sighs and intakes of breath cut out. . The effect was that of emphasing the emotional information expressed in the sighs and pauses of the interviewees on the one hand, and on the other hand, the relative sterility of the spoken word without these natural interjections. By manipulating the sound of the videos, the artist is pointing out that the exhibition experience is appealing to all the senses, not just the visual. This reminds us of the complexity of talking about 'visual' as if it were somehow possible to separate it from the other senses. It also speaks to the experience of the visual matrix, which is an embodied, felt experience and not just a process of visual codification or simple symbolization. Other videos were located inside the archive lockers, creating a claustrophobic sense of confined and private space for the viewer. The found objects included door handles, forgotten mail and an iconic ironing board (Fig. 2 below) that was used as an image to represent to exhibition. One of the Archive's computers displayed a continuous list of names of people who had lived in Bright Street, to a sound of 'tic toc' in headphones, repeated over and 
over. The central theme of the exhibition was described by the artist as 'issues of displacement in the face of adversity and legislation of regeneration and the renewal of place' (Artist's information leaflet).

\section{Place, space and territory}

The exhibition in 2015 brought the reality of a regeneration scheme from the past -the 'Housing Market Renewal Initiative' in Bright Street, Colne, Lancashire, 2005- to a new territory where past is archived and stored for present and future, the Lancashire County Archives in Preston. The Archive exists to 'collect and preserve Lancashire's unique and irreplaceable archives and make them available for exploring personal, family or community history and heritage' (http://www.lancashire.gov.uk/libraries-and-archives.aspx). The exhibition, with its collection of found objects, photographs and videos can be seen as a temporary contribution to the Archive, which brings the artwork close to a historical record. At the same time, the exhibition was an intrusion into the space of the Archive, and put a strain on the more usual use of the lecture room, for example, as noted in the internal evaluation document produced by the Archive.

The arts project and the visual matrix process begin therefore with challenges to 'territories' in space and time, a Deleuzian pre-requisite for creative thinking, 'like a passage from the finite to the infinite, but also from territory to deterritorilaization' (Deleuze and Guattari 1994, p. 180, authors' emphasis). According to Deleuze, it is deterritorialization that rids us of the familiar and routine and creates new 'territories' where creativity is released. This is simply explained in the following example from $A$ Thousand Plateaus:

The orchid deterritorializes by forming an image, a tracing of a wasp: but the wasp reterritorializes on that image. The wasp is nevertheless deterritorialized, becoming a piece in the orchid's reproductive apparatus. But it reterritorializes the orchid by transporting its pollen the orchid by transporting its pollen. (1988 p.10)

The example refers to the ability of the orchid to mimic the female wasp, thus attracting the male wasp, that then inadvertently picks up the orchid's pollen, which is finally transported away for pollination elsewhere

(https://www.youtube.com/watch?v=-h8|3cqpgnA). Orchid and wasp exist in a mutual and creative relationship where two different territories are shared, belonging either to the orchid or the wasp and, in a relational creativity, to both. Similarly, once Bright Street has been deterritorialized from its physical origins in place and time - its territory - and made into a collection of pieces that together form an artwork called Demolition Street, which is subsequently reterritorialized into the Lancashire County Archive, we are engaged in a creative process that creates new territories that are populated by creative 'others' - the visitors to the exhibition. The creation of yet another territory, that of the visual matrix, is an extension of the process, where the contributions of the visitors become a collective social testament and creative act that can be at once individual and collective. Through the visual matrix, the creative experiences of the visitors in contact with the exhibition were 
developed into something more than feedback or assessment of the experience of seeing the artwork. David Armstrong, in discussing the relationship between exterior (outer world) and interior (inner world) images, describes the embodied, emotional and 'becoming' nature of this process:

'When I look at a great painting, say one of Cezanne's still lifes, I do not see the emotional experience that was the origin of Cezanne's transforming work as an artist. Rather, I have an emotional experience myself... I do not just understand or see something new, I become something new.' (Armstrong 2005)

It is in this inner process of 'becoming', which Deleuze directly linked to 'sensation' as part of the artistic experience (Deleuze, 1994, p. 179), that the spectator is no longer what s/he was but 'becomes' a new or different being.

\section{The visual matrix in the Archive}

In Demolition Street I conducted four visual matrices over the period of the exhibition. Each visual matrix consisted of between 10 and 15 participants, some of whom assisted to more than one and others who were only present for a single matrix, making for a different mix of people every time. The participants were recruited via the distribution of flyers, email lists, radio interviews and a press release. A condition of participation was to have viewed the exhibition at least once, and each visual matrix was preceded by an unguided viewing of the exhibition. Each session was 2 hours long and consisted of the visual matrix itself (60 minutes); a break (15 minutes); and a post-matrix discussion (45 minutes). Additionally, the participants were invited to leave the post-matrix discussion for a few minutes at a time, in order to personally video-record a personal thought or feeling in a separate room, if they wanted to. In this way, participants could get a sense of the way their individual image-affects could be simultaneously both individual and shared. This individual recording was then incorporated into the exhibition the next day, thus becoming part of the collective process once more.

The main challenge for a psycho-social researcher new to the method is the gathering together of a group of people who are clear about and committed to the task and to ensure that the session proceeds in a contained and undisturbed manner. If the task is properly explained to the participants and time is given over to the answering of questions; if everyone is committed to staying the full 2 hours; and if the room is quiet and undisturbed, then, more often than not, the visual matrix 'runs itself'.

In the matrix, participants were encouraged to offer images and feelings that they had had while visiting the exhibition or were spontaneously arising during the matrix itself. These images/affect were not necessarily direct reactions to the artwork as object(s) but, in the way described by Armstrong above, expressions of the embodied experiences of each individual shared and interconnected with those of others in the matrix.

\section{Rhizomes, intensities of affect and time(lessness)}


Deleuze conceived of affect as being the expression of multi-layered intensities of emotion distributed in what he called a 'rhizome'. That is to say in an indefinite, directionless inter-connected tangle, where meaning arises through temporary and heterogeneous connections of intensity of affect, which are constantly fluctuating. Deleuze and Guattari's example of the wasp and the orchid is further developed by calling this unlikely partnership a 'rhizome' (1988, p.10). The emergence of meaning in the visual matrix through these expressions occurs in this rhizomatic fashion, where each visual and affective fragment (which I have previously called 'image-affect' (Manley, 2009)) creates unstable relationships with other fragments.

Temporary meanings are constantly emerging and submerging through these inter-connected intensities of image-affects. The relationships between the images are subject to constant potential change during the course of the matrix. They are not fixed meanings. With the introduction of new imageaffects, meanings emerge through a resonance with other previously expressed images, but not in an immediately sequential fashion. An image expressed towards the end of the matrix may well 'ignite' an image that had been expressed at the beginning. A new image may trigger the intensity, value and relevance of an image that had until then been dormant.

This process is highly suggestive of a Deleuzian understanding of 'intensities' of affect. The rhizome of image-affects behaves like Deleuze's description of 'intensive multiplicities', consisting of 'particles' whose 'relations are distances; their movements are Brownian [JM's note: Brownian movement describes the random movement of microscopic particles suspended in a liquid or gas]; their quantities are intensities, differences in intensity' (Deleuze and Guattari 1988, p. 33). Importantly, although this rhizome in the visual matrix may have emerged into being in the time span of the matrix, this visual matrix time is that of Bergson's 'duration' rather than clock time: 'uninterrupted transition, multiplicity without divisibility and succession without interruption' (Bergson 2002, p. 205). Its meanings are not dependent on logical, linear clock time sequences, but are emergent according to intensities within a multiplicity of potential meanings which may occur at any time and in any order. This is why the rhizome in the matrix corresponds to a truly Deleuzian 'rhizomatic multiplicities' as opposed to linear branching out, what Deleuze called 'aborescent' multiplicities' (Deleuze and Guattari 1988, p. 33). By 'aborescent', Deleuze is referring to the multiple branchings out of a plant or a tree, which - unlike the rhizome - follow clear lines of direction.

The participant sensation in the matrix, then, is one of being immersed in a present space of timelessness, Bergson's 'duration', during which expression emerges through a state of 'reverie', in the sense that Bion described (Froggett et al, 2015, note 15). Within the containing space of the visual matrix, a new temporary space-time is established, a new territory. In these conditions, the participants in the matrix are able to enter into creative, visual and deeply affective relationships with each other, leading to profoundly new ways of feeling and thinking that they would not otherwise have had access to: 
[I was] tearful and emotional, the lights were going out for Bright Street. I was wary of workshop and enjoyed it. I liked the open approach ... Don't get that opportunity often. So often in life you are not able to express about how you feel about what you have see, I am more likely to think more deeply about things I see and I want to react to.

(Participant A individual recording)

\section{The individual subsumed in the social}

The visual matrix brings up important questions of the role of the personal in the (social) collective. Due to its innate creative expressivity fostered by the instruction to think and feel in visual images, to describe not explain, and to allow meaning to emerge in intensities of affect that are ignited within a rhizomatic structure of shared thinking, the visual matrix touches on the 'language' of artistic creation. When used in conjunction with an artwork, in this case Demolition Street, this effect may be further enhanced. According to Fuglsang and Sørensen when discussing the mapping of the 'social field' from a Deleuzian perspective, 'aesthetic expressivity has always been about life as it is actualised in affects that move beyond the self-conscious subject' (2006, p.11). The visual matrix does indeed 'move beyond the self-conscious subject'. This is emphasised firstly, by the way the gaze of each of the participants is diverted from engaging with another person as a result of being asked to sit in a 'snowflake' pattern seating arrangement, and secondly, by offering images that 'float' in the space of the matrix, that are not directed at any other participant in the matrix. In this way, each participant in the matrix achieves a degree of anonymity. This is reflected in the way meaning is allowed to emerge in the course of the matrix. The visual matrix is not focussed on individual meanings but rather with whatever sense that can made bu the visual matrix as a whole through a piecing together of the various contributions that have been offered to the space. This visual matrix space or territory is more like a Deleuzian 'zone of indetermination' (Deleuze 1994 , p. 173) than a space of definition and cognition. In the matrix we experience what Deleuze called 'nonorganic life of things', meaning that the creative expression of the matrix creates a vital intensity of affect which is connected together by images in the matrix and unattached to individuals. The 'non-organic life' Deleuze refers to is also that of his concept of the 'Body without Organs' (BwO). What he meant by this was that by giving our individual bodies that encase our individual organs an especial importance and value we hinder ourselves from seeing other, rhizomatically connected systems beyond our immediate knowledge. The visual matrix creates a BwO by removing the importance of the individual in the matrix and replacing this with the 'body' of the shared space, the new-found territory.

\section{Thoughts and feelings from the visual matrix}




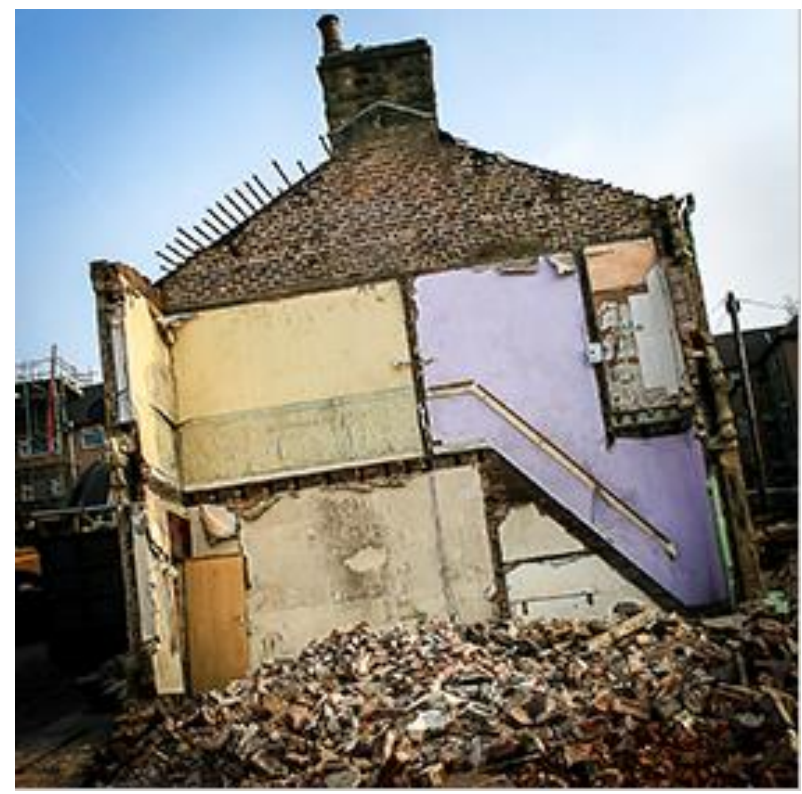

Figure 1: Photograph from Demolition Street

Images such as in Figure 1, encouraged the expression of a series of imageaffects that exposed the gross indignity and inappropriateness of people's personal, private inner lives being exposed to the public, seemingly without care or concern about the personal, the biological reality of each of the affected people who were evicted:

-Exposure, buildings where the wall has come down, you've got the inside outside, that inside is very personal, a home exposed. And the house is almost 'alive', infused with human experience. (VM1)

In this extract, the affective intensity of the image is highlighted through the near personification of the house, resonating with a similar image taken from VM2:

- Individual personalities embodied in the fronts of the individual flats, each flat has a personality in the little black and white images.

Therefore the tearing down of the walls in the demolition process turns the houses into something that is no longer associated with the people, as we see in VM4:

-I couldn't associate the buildings with the people, I thought they were totally divorced from each other because of what had happened

In an example of how experiencing the artwork and the visual matrix brought out the intensity of this dismay at the exposure and powerlessness of the individual, several participants in the fourth visual matrix associated to the sense of the inside being exposed to the outside: 
-I lived in Dalston in the late 60s and there was a half demolished building and pink floral wallpaper exposed to the whole of Dalston Junction and they didn't clear away building very fast in those days and it was just there for months if not years and something painfully intimate being exposed.

-My flat was demolished and my interior walls were exposed to the world and I walked past them every day and that hurt. Your house is supposed to be your sanctuary, then it's not.... Somebody else can take it.

-One of the pictures of the interior walls, I took picture of a demolition site in Bolton, it's almost exactly the same colours as well. (VM4)

In this extract the Deleuzian sense of intensity of affect is clearly displayed. Through description, the affect is allowed to emerge without the mediation of cognitive explanation. The visual matrix specifically demands that no explanations or interpretations be given to people's contributions. It is through the accumulation of the descriptions and the subtle differences between each one, rather than their similarities, that the intensity of affect is intensified. The general feel of 'something painfully intimate being exposed' of the first contribution is combined with the second's very personal 'my flat' and 'my interior walls' being 'exposed to the world' and the feeling of 'hurt' that this generated; this is then connected to the power of an other, 'someone else can take it'. Finally, the third extract suggests the reach of this power by saying that s/he took a picture of another demolition site, which resonated with the demolition pictures of Bright Street. Each communication has been similar but significantly different, thus contributing to an accumulation of affect experienced as intensity.

Difference was expressly connected to intensity by Deleuze, 'intensity, understood as pure difference in itself... that which can be perceived only from the point of view of a transcendental sensibility...' (Deleuze 2004, p. 181). For Deleuze, this transcendental sensibility is specifically differentiated from 'empirical sensibility' (ibid, p.181). In the context of Demolition Street and the visual matrices, I understand the 'transcendental' to reside in the lived experience of the visitors to the exhibition, later shared in the creative space of the visual matrix. This shows how the visual matrix can be used to allow for the emergence of profoundly affective responses to our (social) 'collective' domain.

This affective understanding of the nature of the communication in the matrix was developed in different ways. For example, it was compared to what might be lying beneath the rubble:

-I wonder what's buried underneath?

-What lies beneath the surface, urban archaeology

-What people call a home. (VM2)

In this example, 'beneath the surface' seems to echo the idea that this language of affects is indeed unconscious and this is identified with the 'home' 
that defines the self and the value of each person rather than the houses that are demolished as valueless.

It is within the potential space of the visual matrix that the participants in the matrices are able to delve into questions of the nature and meaning of time. This joins together the sense of disjointed time, or time standing still produced by the images of Demolition Street and the actual thinking process of the visual matrix itself. In VM2 this is introduced through an image of Dr Who that is a good example of the way creative space of the visual matrix works in making connections between the value of people and the passing of time in the conjuring of a succinct or 'condensed' (in Freud's sense of the word) image:

-Dr Who

-Who, being an operative word, who had lived there? Who do the doors belong to? And then what, what had happened to them? Where had they gone? Where were they now? Who are their descendants? How have they all changed?

-Timelord -Image of one of the old Dr Whos coming down in his Tardis in the middle of Bright Street and getting people into it and going back in time. (VM2)

Through the exhibition and the visual matrix, the participants have, so to speak, been transformed into 'Timelords', enabling them to go back in time, not only the actual time of Demolition Street before and after demolition, but to the undefined time of childhood past and nostalgia, where people ask themselves about their own identities, 'Who' they are as much as 'Who' the residents of Bright Street were. Demolition Street evoked for many the loss of a spirit of community past, and with it an important sense of community warmth despite the rational knowledge that by moving on living standards have risen. Once again, the visual matrix enables a perspective of affect that challenges the rational:

-A sense of who's been there, thinking of people in different eras, different styles, different dress, different outlook, different interests, different music, feeling that it was all there in the past, almost like ghost voices, wondering what it meant to those people. And also a sense that I probably wouldn't have liked to live there, and people might have moved on to something that might have been a better standard, so, in some cases it's already positive, but a sense that warmth of the community and togetherness and sharing might have been progressively lost (VM2)

VM2 continues to connect the past warmth of community, personally felt, with the complex affect of pride:

-Reminds me of the mill towns of my childhood in New England, the steep hills, poverty, and remembering the pride, very proud... 
-My grandma was proud of her front step and used to clean it as a point of pride

-You could eat your dinner off those steps couldn't you?

-Sparkling...

-She did and the neighbours did as well.

-Point of pride... (VM2)

Furthermore, the locus of pride returns once again to the house as representative of the feelings of the people within them, and, therefore, with an understated comment on the effects of faceless demolition:

Cleanliness and pride: but the houses were completely clean and kept with pride. The house meant everything. (VM2)

The creative experiences of exhibition and visual matrix led the third visual matrix to conclude that maybe art itself could reinstate community pride by citing the intervention of Turner Prize winners Assemble. In this there is a hope that art can indeed, through an aesthetic sensibility that is otherwise lost, be the hope for the future of these homes. Rather than being demolished, maybe they could have been rebuilt like the renovated houses of Assemble. The creative thinking of the matrix makes such a dream possible:

-The young people, artists, I don't think it's Toxteth, who are candidates for the Turner prize, [Assemble] - I have a visual image that was in the paper, but also a real sense of hope in using houses differently, reminded me of Chicago? [Detroit], because the houses are not going to be used, people are not interested in them, we can be interested in completely different things, floors can come down, you can just have a double height room. We can do what we like, just that sense of possibility, and creating something that looked so beautiful and different. (VM3)

The alternative to this was found in a resilient humour, and was introduced through regular reference to a particular sense of British humour -the Carry On films, Morecombe and Wise, Monty Python - that never seems to die. The ultimate humorous connection between resilience in the face of falling houses comes in the image of Buster Keaton standing firm while the façade of a house literally falls through him:

-The best one is Buster Keaton where the front of the house falls down and he's standing still standing there, millimetre perfect. He's standing just in the window space. (VM4)

The complex example of Dr Who discussed above is also echoed in a link made between comedy, science fiction and time in a reference to Red Dwarf:

-A re-run of Red Dwarf, never seen this one before, a photographic developing solution got contaminated and whenever it produced a 
photograph, it comes alive and you go back to the moment as long as you don't step out of the frame. (VM4)

In this case, the participants in the matrix are given a similar opportunity to go back to the past, but the comedy acts as a buffer to disappointment and a further indication of resilience.

\section{The 'social' and the use of the visual matrix as a psycho-social method}

Where psycho-social studies diverges from other psychoanalytically informed practice is in its marriage with the 'social'. The visual matrix is truly a psychosocial method in the way it merges psyche and society. The use of the method in the context of a socially engaged artist makes this particularly illustrative of the value of the visual matrix as a psycho-social method.

Bruno Latour - influenced by Gabriel Tarde's view of the social as distinct from Durkheim's - goes to great lengths to redefine 'social' as being similar to an interconnectedness between all things, not just people, emphasising description rather than explanation as a primary aim of social investigation, and difference rather than similitude as the key to meaning-making. For Latour, 'the factors gathered in the past under the label of a 'social domain' are simply some of the elements to be assembled in the future in what I will call not a society but a collective' (Latour, 2005, p. 14, original emphasis). Adopting this approach frees us to discuss process, association, movement and exploration, rather than (social) objects in themselves. The viewing of such potential objects - the artwork as object for example, or a 'social problem' such as urban regeneration - is instead viewed as a participation in a network of connections through associations and relational inter-subjectivities. This 'collectivity' emerges as an indistinguishable web of relationships between things and people as subjects in relationship with a creative process that makes the whole network available for experience. This inter-connected network thus redefines the object of the 'problem' as a human and not-sohuman process of contemplation where many inconclusive avenues of meaning can co-exist in an undeniable complexity.

I have used Latour in this context to bring up questions of the definition of the 'social' because this is crucial in approaching Demolition Street as a work of art that may be connected to a 'social' problem or issue and yet retains its status as something that exists in itself, a non-fixed, ephemeral body of interconnectedness which is indeterminate in its relationship to the 'social'. In the visual matrix, we are able to maintain an idea of 'social' that is at once societal, personal and shared within the context of the visual matrix. This is what Deleuze called a 'bloc of sensations, that is to say, a compound of percepts and affects' (Deleuze, 1994, p. 164). Just as 'affect' is more than 'affection', 'percept' is more than 'perception' (ibid). According to Deleuze, both affect and percept refer to an inwardly embodied movement that combine mind and body and are powerful enough to produce the sensation that they exist beyond the self. Perception and affection are simple acts of seeing and feeling, whereas percept and affect are active movements of intensity: 
'Percepts are not perceptions, they are packets of sensations and relations that outlive those who experience them. Affects are not feelings, they are becomings that go beyond those who live through them (they become other)' (Deleuze, quoted in Thrift, 2008, p. 116 ).

Similarly, Deleuze's view of a work of art was that it was a 'being of sensation and nothing else: it exists in itself' (Deleuze, 1994. P. 164).

In these ways, we are able to inter-connect the participants in the visual matrix within a 'bloc of sensations' that includes the participants themselves, the artwork, and the actual street itself in ways that blur the distinction between reality and imagination.

\section{A Deleuzian method}

Although a recent publication has been dedicated to 'Deleuze and Research Methodologies' (Coleman and Ringrose, 2013), these studies have largely been focused on using a Deleuzian approach within existing methodologies ('ethnography, group and individual interviewing, film-making and online research' (ibid, p. 3). In the present chapter, I am suggesting that the method itself can be viewed from a Deleuzian perspective.

This will also give meaning to Beuy's famous dictum 'Every human being is an artist' (Beuys, quoted in Harrison and Wood, 2003 p. 929), because the visual matrix, I contend, encourages a space of creativity for the participants in association with the artwork and each other, putting each participant in the role of artist for the duration of the visual matrix. This is where Deleuze and Beuys can be seen to resonate: In Beuys, art is the democratic and creative space, where each person is in creative conjunction with the other: 'The most important thing to me is that man, by virtue of his products, has experience of how he can contribute to the whole and not only produce articles but become a sculptor or architect of the whole social organism' (Beuys, quoted in ibid, p. 904). And for Deleuze, 'Art begins not with the flesh but with the house. That is why architecture is the first of the arts' (Deleuze and Guattari, 1994, p. 186). Both conceive of an architecture as a 'territory', (Deleuze) or 'whole social organism', (Beuys), which will lead to different creations outside this territory or organism: Deleuze's 'Universe' and 'deterritorialization' (ibid, p. 186); and Beuy's 'organization of society' (Beuys, quoted in Harrison and Wood, 2003, p. 904). Beuys echoes Deleuze's 'bloc of sensations' when he states that 'art looks more towards a field where sensitivity is developed into an organ of cognition and hence explores areas quite different from formal logic' (Beuys, ibid, p. 905). Whatever is created in the territory has to expand out into something beyond, 'from endosensation to exosensation' (Deleuze and Guattari, 1994, p. 185). Deleuze's metaphorical use of 'House' is particularly apt to this study, where the artwork and the visual matrix are engaged with demolition of houses, where what was inside the house is exposed to the outside and where, in the visual matrix, the deterritorialization of the artwork produces a new creative 'territory' in the space of visual matrix. 
The essential difference according to Deleuze in his book on Francis Bacon and art is between a form of representation and a more ineffable experience of affect. Just as Deleuze believes Bacon's art is non-representational and therefore more closely aligned to affective experience, so is the experience of the visual matrix. For Deleuze, the BwO is 'flesh and nerve' and experience runs through the whole like a 'wave' of affective intensities which become 'sensation ... linked to the body', whereupon 'it ceases to be representative and becomes real' (Deleuze 2005, p. 33). Take for example the image of the ironing board, which was one of the iconic images from the exhibition (Figure 2) and led to various expressions of affect in the visual matrices.

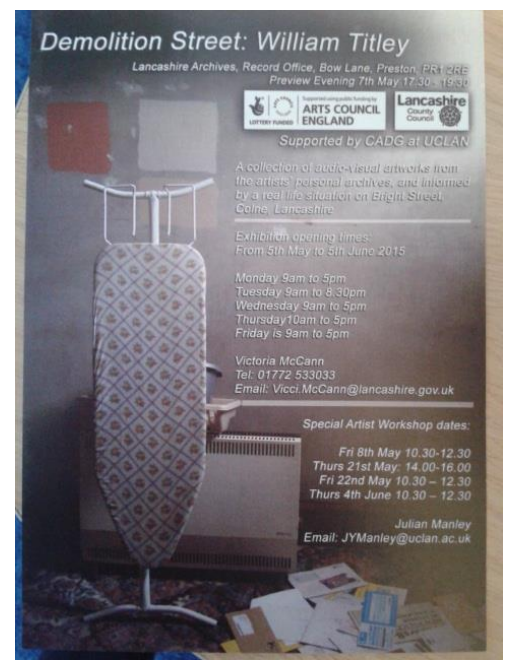

Figure 2: The image of the ironing board on the exhibition poster

The following passage from the second visual matrix engages and develops the affective resonance of the image of the ironing board:

-My ironing board is wooden, and my mum's neighbour who came from Jamaica gave it to me as a wedding present, and even though it's the most rickety rackety thing... it's had lots of covers...I've still got it, I still use it, rarely because I rarely iron, but I do still use it...

-One doesn't think of an ironing board having a history usually...

-Remember my mother with her wooden ironing board, and she did iron lots, ironing in front of the telly.

-Yep, watching Coronation Street...that's what mine did, and I used to have to learn how to iron by practising ironing my dad's hankies

-Tea towels...

-Ironing sheets...

-sheets, tea towels, socks, pants...

-Me dad's socks...

-Quite right! (VM2)

As revealed in the bemused comment 'One doesn't think of an ironing board having a history usually', the ironing board's lowly status, especially this cited old fashioned wooden one, is an unlikely candidate for any form of representation. Instead, what we have is experience and affect. In its use, it encourages a process of care and attention that links to the memory of a 
wedding present that is not representative of the love in the marriage but of the experienced reality of ageing and preservation, care and reflection, and renewal. It has a value in experience despite being 'rickety rackety'. It has a deeper connection with community, since it was the mother's neighbour who gave it to her. It does not represent community but it expresses some of the affect of that community that endures in the speaker. The experience of everyday care, shared by others in the matrix, is important precisely because of its everydayness. The list of especially ordinary clothing that has been ironed, ends up with 'Me dad's socks', which brings in a sense of humour which itself is an expression of affect, the humour mentioned above connected to resilience. The wave of affect thus expressed is that of the BwO of the matrix. It does not belong to any particular individual. The multiplicity of meanings therein exists as a systemic whole, the collage of image-affects.

\section{Smooth space and becomings in the visual matrix}

This BwO of the matrix is only made possible by the containing space of the matrix being made openly available for free association, by being, in Deleuzian terms, a 'smooth space', not 'striated'. The 'smooth space' is that of the 'nomad', where travel, like process, is an end in itself rather than destination. In the visual matrix, we have a smooth space where images, thoughts and affect can arise, connect, disappear and reappear without any set order or destination. 'Smooth space ... is a space of affects, more than one of properties' (Deleuze 1988, p. 479). In the visual matrix this leads to a sense of 'becoming', as we have already noted in the fusion of house and person, 'becoming house'. It is through the free flowing associations of the matrix, unbound by thought conventions that unexpected couplings can occur and merge as becomings. Another important example of becoming in the matrices include becoming a resident of Bright Street through the process of experiencing the 'smooth space' of affect in the matrix where such a journey is made possible through the futuring 'magic' of Dr Who or the Red Dwarf. The smooth space of the visual matrix, then, is far removed from 'striated' space, where thinking moves in specific lines and directions that are predetermined by an already conceived outcome.

The future time implied in Dr Who and the Red Dwarf seems at first to belie the archival nature of the exhibition and its location in the Lancashire County Archives. At first sight, it would seem that Demolition Street should be about a lost past, and indeed many of the matrices evoked a sense of lost childhood and nostalgia for a community spirit that has disappeared. However, what the visual matrix shows is that the aesthetic experience of the visitors to the exhibition is such that past, present and future can be combined into a single experience that resonates with Bergson's concept of time and reality, where what counts in the reality of the experience is the intensity of particular points and levels of affects as held together by the aesthetic experience of the matrix. This experienced reality is unlike the archived reality. In that sense it is virtual. However, in the moment of shared creative affect, the virtual becomes real and the future is just as tangible as the past. This is the process of duration that Bergson described in his treatises on time, as adopted by Deleuze: 
'All these levels or degrees and all these points are themselves virtual. They belong to a single Time; they coexist in a Unity; they are enclosed in a Simplicity; they form the potential parts of a Whole that is itself virtual. They are the reality of this virtual. (Deleuze 1991, p. 100, author's italics)

This is why the experience of the visual matrix is a creative experience. Since an 'objective' reality cannot function in this new space -the space of the Archive is invaded, so to speak, by the new territory of the artwork and then the visual matrix - a new, created/creative/creating reality has emerged. In these conditions, as Zepke points out, art 'is an experience of becoming, an experiential body of becoming, an experimentation producing new realities' (Zepke 2005, p.4), and the aesthetic experience of the artwork is inseparable from ontology: 'Aesthetics then, is inseparable from ontology, because experience is, for Deleuze and Guatarri, irreducibly real' (ibid, p.3).

The way Deleuze himself puts it, in his discussion of Bacon, again strongly resonates with the experience of the artwork and the free associative experience of the visual matrix:

'It is like the emergence of another world. For these marks, these traits, are irrational, involuntary, accidental, free, random. They are nonrepresentative, nonillustrative, nonnarrative. They are no longer either significant or signifiers: they are assignifying traits. They are traits of sensation...' (Deleuze 2005, p. 71).

\section{'Every human being is an artist'}

One of the participants who recorded a personal feedback video commented:

'Don't know the people but I feel I do. I am those people.'

(Participant B personal video recording)

This clear statement of becoming is one of the keys to the sense of creative process undergone by the participants to the visual matrices following the experience of engagement with Demolition Street. In this process, it is clear how each participant to the visual matrices can be considered an artist, creating new realities out of the virtual; and it is in this virtual that an experience of intensity of affect is created that makes the virtual real. In this way, the dual experience of the visual matrix in conjunction with the artwork has created a new virtual/real 'territory' out of the deterritorialisation of Bright Street and its relocation into a new assemblage of Demolition Street, the Archive and finally the visual matrix. Along with the shifting territory or locus, time is redefined in a Bergsonian and Deleuzian sense, so that past, present and future can be experienced in a new moment. Such a new moment within a new space creates the Deleuzian 'plateau', an idea that Deleuze acknowledged was suggested by Gregory Bateson (2000). Each 'plateau' is a 'smooth space' of free flowing association that occurs in the visual matrix. A new 'body' of interconnected, rhizomatic intensities of affect is created: a 
Body without Organs. Art, according to Bateson, is a primary process, therefore an unconscious process, where 'there are no markers to indicate to the conscious mind that the message material is metaphoric' (Bateson 2000, p. 140). This well describes the process of the visual matrix, almost an artwork in itself, and the participants almost artists too, becoming artists.

\section{Conclusion: From self to 'no self'}

The visual matrix method presents the psycho-social researcher with a means of gathering complex, nuanced data that is shared and rooted in affect. The theoretical siting of this work within the philosophical Deleuzian paradigm clarifies the method as a whole and identifies the visual matrix as an epistemic tool for an ontological position that goes beyond the assumptions behind the psychoanalytically informed methods that are more usual in psycho-social studies. Conceptually, I believe that the visual matrix provides a method that brings together many strands from the broad domains of psychology and philosophy, which somewhat reluctantly seem to flow together and apart in a 'love-hate' or 'approach-avoidance' fashion (O'Donohue and Kitchener 1996, p. xiii). It also speaks to Latour's 'associology' and his attempts to reconfigure sociology. We have, therefore, the beginnings of a new ontology that is 'holistic' in its embracing of what might otherwise have been viewed as separate ways of understanding the world. The bringing together of the 'psycho' and the 'social' is certainly part of this new vision.

Previous publications have indicated some of the specific advantages of using the visual matrix in research, in particular where complex issues which are difficult to express are part of the research project, where understanding affect is especially important, and where the researcher is seeking shared data rather than individual feedback (Froggett et al 2015; Manley et al 2016; Manley and Roy 2017). We can add to these the suggestion that the visual matrix is an inherently creative method that can be used to bring the past to present experience: each participant in the visual matrix temporarily becomes an artist and a 'timelord' of the visual matrix. In analysing the data, the psycho-social researcher places herself in an ontological position that reassesses history and fact. The data may not be empirical 'fact', but it is still 'true' as felt experience. Deleuze believed that philosophy was the act of creating ideas. The visual matrix provides the shared created ideas of the participants, with their roots in affect. There is often a joy in the creative act even if the material is negative or troublesome - that gives value to the process itself. When the research subjects are participating in this process of creation, there is a predisposition to 'say what you really feel'. This is supported by the sensation in the visual matrix that each individual is somehow saying what everyone else feels, what the space itself 'feels'. The self, which is often so important in psychoanalytically informed research, here becomes a 'non-self', where group dynamic processes such as Bion's Basic Assumptions are largely attenuated due to this sense of 'non-self' of the visual matrix. The visual matrix is therefore useful in its application to an understanding of what might be termed a 'shared unconscious', where the matrix becomes something like a BwO. The visual matrix is therefore 
particularly effective where the research is focussed on shared affect rather than individual knowledge.

We might ask ourselves how self relates to non-self and what kind of paradox is usefully being evinced here. The nexus that links self and non-self is creativity. It is only through the creative imagination, the suspension of disbelief that the self within each individual can also be the non-self that belongs to the whole in the visual matrix. This process of the creative imagination is an experiential one, therefore not representative of social 'fact'. It is, instead, a process experienced as social reality. The visual matrix is a research method that encourages every human being to be an artist, including the researcher.

(8,099 words, including references)

\section{References}

Armstrong, D. ( 2005) Organisation in the Mind. London: Karnac

Bateson, G. (2000) Steps to an Ecology of Mind. London and Chcago: University of Chicago Press.

Berman, H. and Manley, J. (Forthcoming 2017) Social Dreaming and creativity in South Africa: Imag(in)ing the unthought known. In Adlam, J., Gilligan, J., Kluttig, T. Lee, B. \& Young, J.L. (eds.) Creative States:

Overcoming Violence. London: Jessica Kingsley.

Bishop, C. (2012) Artificial Hells. London: Verso

Coleman, R. and Ringrose, J. (2013) Deleuze and Research Methodologies. Edinburgh: Edinburgh University Presss

Deleuze, G. and Guatarri, F. (1988) A Thousand Plateaus. London: Continuum

Deleuze, G. and Guatarri, F. (1994) What is Philosophy? London: Verso

Deleuze, G. (1991) Bergsonism. New York: Zone Books

Deleuze, G. (2005) Francis Bacon. London: Bloomsbury

Froggett, L., Manley, J., and Roy, A. (2015) 'The Visual Matrix Method: Imagery and Affect in a Group-based Research Setting', Forum: Qualitative Social Research

Fuglsang, M. and Sørensen, B.M. (2006) Deleuze and the Social. Edinburgh: Edinburgh University Press. 
Harrison, C. and Wood, P. (2003) Art in Theory 1900-2000. London:

Blackwell.

Jackson, S (2011) Social Works. London: Routledge.

Karolia, I. and Manley, J. (Forthcoming 2017) ' 1 in 5 Brit Muslims' Sympathy for Jihadis': The lived experience of UK Muslims following the terror attacks in Paris. In Adlam, J., Gilligan, J., Kluttig, T. Lee, B. \& Young, J.L. (eds.) Creative States: Overcoming Violence. London: Jessica Kingsley.

Latour, B. (2005) Reassembling the Social. Oxford: Oxford University Press.

Lawrence, W.G. (2005) An Introduction to Social Dreaming: Transforming Thinking. London: Karnac

O'Donohue, W. and Kitchener, R.F. (eds) (1996) The Philosophy of Psychology. London: Sage

Manley, J, (2009), 'When words are not enough', Chapter 4 in Clarke, Simon and Hoggett, Paul (eds.), Researching Beneath the Surface. London: Karnac

Manley, J (2014) 'Gordon Lawrence's Social Dreaming Matrix: background, origins, history and developments'. Organisational and Social Dynamics Vol $14 / 22014$

Manley, J., Roy, A. and Froggett, L. (2015) Researching Recovery from Substance Misuse Using Visual Methods, in (Eds.), L. Hardwick, R. Smith and A. Worsley, Innovation in Social Work Research, London: Jessica Kingsley

Manley, J. \& Roy, A. (2016) 'The visual matrix: a psycho-social method for discovering unspoken complexities in social care practice', Psychoanalysis, Culture and Society, doi:10.1057/s41282-016-0037-5 (http://link.springer.com/article/10.1057/s41282-016-0037-5)

Manley, J. \& Trustram, M. (2016) "Such endings that are not over': The slave trade, social dreaming and affect in a museum', Psychoanalysis, Culture and Society, doi:10.1057/s41282-016-0032-x (http://link.springer.com/article/10.1057/s41282-016-0032-x)

Thrift, N. (2008) Non-Representational Theory. London: Routledge.

Zepke, S. (2005) Art as Abstract Machine. Ontology and Aesthetics in Deleuze and Guatarri. London: Routledge. 
